\title{
Identification of Legionella from clinically diagnosed pneumonia patients and environmental samples
}

\author{
Jahan $\mathrm{R}^{1}$, Tarafder $\mathrm{S}^{2}$, Saleh $\mathrm{AA}^{2}$, Miah $\mathrm{MRA}^{2}$ \\ 1. Department of Microbiology, Shaheed Suhrawardy Medical College, Dhaka, 2. Department of Microbiology \\ and Immunology, Bangabandhu Sheikh Mujib Medical University (BSMMU), Dhaka. \\ Email: jahan_rownak@yahoo.com
}

\begin{abstract}
Legionnaires' disease is a multisystem disease with life-threatening acute and severe form of pneumonia which is responsible for $2-9 \%$ pneumonia with high mortality. Eighty six respiratory tract samples and urine were collected from clinically diagnosed pneumonia patients and 12 water samples were collected from different environment. Identification of Legionella was done by culture and Polymerase Chain Reaction (PCR) of respiratory tract samples and environmental samples and Legionella Antigen (Ag) in urine was detected by Immunochromatographic test (ICT). Legionella was identified from $4(4.65 \%)$ clinically diagnosed pneumonia patients of which $1(1.16 \%)$ case was culture positive, $1(1.16 \%)$ case was urine ICT positive and PCR was positive in all four cases. Of the 12 water samples tested, 4 (33.33\%) samples were Legionella positive by PCR but culture results of these samples were negative. Identification of Legionella should be done by PCR in parallel with culture and urine ICT. Detection of Legionella in environmental samples is also needed to explore possible links between the water sources and disease transmission in population.
\end{abstract}

\section{Introduction}

Legionnaires' disease (LD) is a multisystem disease with life-threatening acute and severe form of pneumonia caused by several species of Legionella. ${ }^{1}$ It is responsible for $2-9 \%$ pneumonia with a mortality rate between $5 \%$ to $10 \%{ }^{1}$ and this rate may exceed $50 \%$ for elderly or immunocompromised patients. $^{2}$ Legionnaires' disease can account for up to $30 \%$ of pneumonia requiring admission to intensive care unit (ICU). ${ }^{1}$ Currently, there are 50 species comprising 70 distinct serogroups in the genus Legionella of which 20 species have been reported to cause human pneumonia. ${ }^{1}$ Approximately $90 \%$ Legionella induced pneumonia is caused by Legionella pneumophila which comprises 16 different serogroups (sg). ${ }^{1}$ There is strong evidence that the risk of Legionnaires' disease (LD) might be higher under certain environmental condition like warm, humid and rainy weather, thus this weather shown associated with higher incidence of Legionnaires' disease in tropical countries. ${ }^{3,4}$ Bangladesh is a tropical country with monsoon-type climate including hot, humid and rainy summer which might be associated with higher incidence of Legionnaires' disease.

In Bangladesh, annual rate of new pneumonia cases is six million which is the world's fourth highest annual pneumonia rate. ${ }^{5} \mathrm{~A}$ study has been carried out in Bangladesh which reported 3\% children with pneumonia admitted in a hospital had high antibody titre against Legionella species. ${ }^{6}$ However, no study has been done in Bangladesh to identify the Legionella in adult pneumonia patients. In many studies, Legionella has been found to be a common cause of pneumonia and the clinical manifestations were more severe and the mortality was higher when compared with pneumonias of other aetiology. ${ }^{7}$ However, this is due to delay in diagnosis and suboptimal antibiotic therapy, rather than enhanced virulence of Legionella. ${ }^{7}$ The rate of Legionella pneumonia amongst adults in our country may be underestimated owing to practical difficulties such as lack of a productive cough and availability of diagnostic methods. ${ }^{8}$ Pneumonia in adult and elderly patients is a common and serious problem that has different clinical presentation and higher mortality. ${ }^{9}$ Elderly patients may present with atypical symptoms other than the typical respiratory symptoms of pneumonia that lead to delay in diagnosis and initiation of treatment and may be responsible for higher observed mortality. ${ }^{10}$

Considering long summer climate, wet humid weather patterns and high incidence of pneumonia in Bangladesh, it is imperative to study the existence of Legionella by early detection for timely intervention and the correct choice of antimicrobial therapy to reduce the mortality. Moreover, Legionella pneumonia is acquired by 
inhalation of aerosolized water or microaspiration of water droplets contaminated by Legionella from natural or man made water sources such as ponds, lakes, potable water systems (e.g., showerheads, taps) and air conditioning systems. ${ }^{11}$ Besides, as the transmission of Legionella from person to person has never been observed ${ }^{12}$, prevention needs to concentrate on the elimination of this pathogen from water and aerosol producing systems. Thus, rapid and precise detection of Legionella in water systems is very important for risk prediction and the elimination of Legionella from possible infection sources. ${ }^{1}$ So, this study has been designed to identify Legionella from clinically diagnosed pneumonia patients of adult age group by culture, urine ICT and PCR and from environmental samples by culture and PCR.

\section{Materials and Methods}

Specimens: Respiratory tract samples were collected from 86 clinically diagnosed pneumonia patients admitted in General Medicine ward and ICU of Bangabandhu Sheikh Mujib Medical University (BSMMU) during the period of August 2012 to July 2013. Of which 50 were sputum samples and 36 were tracheal aspirates (TA). Urine was collected from all 86 patients.

A total of 12 water samples were collected from different environment. Three water samples were obtained from three ponds, one from a hotel, five from General Medicine ward and ICU of BSMMU and two from biosafety laboratory of Department of Microbiology and Immunology, BSMMU. One shower head swab sample was collected from General Medicine ward, BSMMU.

Sample processing ${ }^{13}$ : Thick sputum samples were diluted by PBS. Sputum or TA was mechanically homogenized by vortexing for five minutes. After vortexing, sputum and TA were centrifuged at $3000 \mathrm{~g}$ for 10 minutes. Supernatant was discarded using a sterile pipette and concentrated sediment was resuspended to be used for culture and PCR.

Water samples were concentrated by filtration by pouring the samples into sterile $47 \mathrm{~mm}$ filter funnels assembly containing a $0.22 \mu \mathrm{m}$ polycarbonate filters. After filtration, the filters were removed aseptically from the holder with sterile forceps and placed into a sterile $50 \mathrm{ml}$ centrifuge tube containing $5 \mathrm{ml}$ of sterile water. The centrifuge tube was then vortexed for one minute to free bacteria and organic material from the filters and the water was kept for culture and PCR. Swab containing tube was shaken vigorously for two minutes to release the bacteria. Swab stick was discarded and the water was kept for culture and $\mathrm{PCR}^{14}$.
Culture $^{14-16}$ : The sputum, TA and water were divided into two categories: untreated and acidtreated by $0.2 \mathrm{M} \mathrm{KCl}-\mathrm{HCl}$ buffer $(\mathrm{pH}-2.2)$. For acid treatment, approximately $0.5 \mathrm{ml}$ of specimen was added to $2.5 \mathrm{ml}$ of a $0.2 \mathrm{M} \mathrm{KCI-HCI}$ solution to achieve a 1:5 dilution and kept for five minutes. Approximately $0.01 \mathrm{ml}$ of both processed sample without decontamination and processed sample decontaminated by acid buffer were inoculated on the selective buffered charcoal yeast extract (BCYE) medium (HiMedia, India) supplemented with L-cysteine, iron and antibiotics and BCYE medium without antibiotics. The media were incubated at $37^{\circ} \mathrm{C}$ and were examined daily for seven days for the presence of growth. The plates were held for a maximum of two weeks before being discarded as negative. If growth was present then identification of the Legionella was done by colony morphology, gram staining, biochemical test and PCR. Round, glistening, convex, 3-4 mm diameter, frosted glass colonies were used for identification. Gram staining was done to see the thin, faintly stained gram-negative morphology of Legionella. Legionella were catalase-positive, oxidase positive, liquefy Gelatine and Legionella pneumophila hydrolyses sodium hippurate.

Urine Ag Immunochromatographic test (ICT): Legionella pneumophila serogroup one urinary antigen was detected by Legionella ICT kit (Binax NOW) following the manufacturer's instructions.

PCR: The test was carried out by amplification of Legionella gene fragment 16SrRNA with the use of primers pair JFP and JRP. The sequences of the used primers were as follows ${ }^{17}$ :

Forward primer JFP:

5' -AGGGTTGATAGGTTAAGAGC-3';

Reverse primer JRP:

5' -CCAACAGCTAGTTGACATCG-3'.

PCR was performed in a final reaction volume of $25 \mu \mathrm{l}$ in a PCR tube, containing $12 \mu \mathrm{l}$ of master mix (mixture of dNTP, taq polymerase, $\mathrm{Mgcl}_{2}$ and PCR buffer), $1 \mu \mathrm{l}$ of forward primer and $1 \mu \mathrm{l}$ of reverse primer (promega corporation,USA) of Legionella, $3 \mu \mathrm{l}$ of extracted DNA and $8 \mu \mathrm{l}$ of nuclease free water. After a brief vortex, the PCR tube was centrifuged in micro centrifuge for few seconds. Amplification was carried out in DNA Thermal Cycler and comprised initial denaturation at $95^{\circ} \mathrm{C}$ for 15 minutes followed by 36 cycles consisting of $94^{\circ} \mathrm{C}$ for $30 \mathrm{~s}, 59^{\circ} \mathrm{C}$ for $40 \mathrm{~s}$, and $72^{\circ} \mathrm{C}$ for $40 \mathrm{~s}$ and a final extension at $72^{\circ} \mathrm{C}$ for $20 \mathrm{~min}$. Then the product was held at $4^{\circ} \mathrm{C}$. After amplification product was processed for gel documentation or kept at $-20^{\circ} \mathrm{C}$ till tested. The size of the amplified DNA fragments was $386 \mathrm{bp}$. PCR products were 
identified by electrophoresis in $2 \%$ agarose gel with ethidium bromide.

\section{Results}

Out of 86 pneumonia patients, $4(4.65 \%)$ cases were Legionella positive of which $1(1.16 \%)$ case was culture positive, $1(1.16 \%)$ case was urine ICT positive and PCR was found to be positive in $4(4.65 \%)$ cases. Out of 86 pneumonia patients, $2(2.33 \%)$ cases were only PCR positive, 1(1.16\%) case was both culture and PCR positive and $1(1.16 \%)$ case was both urine ICT and PCR positive. No case was only culture positive or urine ICT positive. Both culture and urine ICT positive cases were also positive by PCR (Table I).

Table I: Frequency of Legionella detection by culture, urine ICT and PCR in pneumonia patients $(n=86)$

\begin{tabular}{lcc}
\hline \multirow{2}{*}{ Methods } & \multicolumn{2}{c}{ Positive } \\
& No. & $\%$ \\
\hline Only culture positive & 0 & 0 \\
Only Urine ICT positive & 0 & 0 \\
Only PCR positive & 2 & 2.33 \\
Culture and PCR positive, ICT negative & 1 & 1.16 \\
Urine ICT and PCR positive, Culture negative & 1 & 1.16 \\
\hline Total & 4 & 4.65 \\
\hline
\end{tabular}

Identification of Legionella from tracheal aspirate and sputum by culture and PCR and from urine by ICT is shown in Table II. Among 86 respiratory tract samples, 36 were tracheal aspirates and 50 were sputum. Out of 36 tracheal aspirates, Legionella was positive by culture in $1(2.77 \%)$ case and $3(8.33 \%)$ cases were identified by PCR. Out of 50 sputum specimen, no case was Legionella culture positive but $1(2 \%)$ case was identified by PCR. Out of 86 urine samples, $1(1.16 \%)$ case was positive by urine ICT.

Table II: Identification of Legionella from tracheal aspirate and sputum by culture and PCR and from urine by ICT

\begin{tabular}{ccccc}
\hline $\begin{array}{c}\text { Name of } \\
\text { specimen }\end{array}$ & $\begin{array}{c}\text { No. of } \\
\text { specimen }\end{array}$ & $\begin{array}{c}\text { Culture } \\
\text { positive } \\
\text { No. }(\%)^{\mathrm{a}}\end{array}$ & $\begin{array}{c}\text { PCR } \\
\text { positive } \\
\text { No. }(\%)^{\mathrm{a}}\end{array}$ & $\begin{array}{c}\text { ICT } \\
\text { positive } \\
\text { No. }(\%)^{\mathrm{a}}\end{array}$ \\
\hline $\begin{array}{l}\text { Tracheal } \\
\text { aspirate }\end{array}$ & 36 & $1(2.77)$ & $3(8.33)$ & NA* $^{*}$ \\
$\begin{array}{l}\text { Sputum } \\
\text { Urine }\end{array}$ & 50 & $0(0)$ & $1(2.00)$ & NA \\
\hline
\end{tabular}

${ }^{a}$ Percentage done on individual total sample

* NA- Not applicable, ** ND-Not done

The distribution of Legionella detected from environmental samples by culture and PCR is shown in Table III. Out of 12 environmental samples, 4(33.33\%) samples were found to be Legionella positive of which Legionella was detected in $3(25 \%)$ ponds and $1(8.33 \%)$ supply water in General Medicine ward by PCR, but the culture results of these samples were negative.
Table III: Distribution of Legionella detected from environmental samples by culture and PCR $(n=12)$

\begin{tabular}{|c|c|c|c|c|}
\hline \multirow[t]{2}{*}{ Source } & & Total & $\begin{array}{l}\text { Culture } \\
\text { positive }\end{array}$ & $\begin{array}{c}\text { PCR } \\
\text { positive }\end{array}$ \\
\hline & & & No. $(\%)$ & No. $(\%)$ \\
\hline Pond water & & 3 & $0(0)$ & $3(25)$ \\
\hline Hotel water & & 1 & $0(0)$ & $0(0)$ \\
\hline \multirow{3}{*}{ ICU } & Supply water $(n=1)$ & & $0(0)$ & $0(0)$ \\
\hline & Air condition $(n=1)$ & 3 & $0(0)$ & $0(0)$ \\
\hline & Dialysis Machine $(n=1)$ & & $0(0)$ & $0(0)$ \\
\hline \multirow{3}{*}{$\begin{array}{l}\text { General } \\
\text { Medicine } \\
\text { ward }\end{array}$} & Supply water $(n=1)$ & & $0(0)$ & $1(8.33)$ \\
\hline & Air condition $(n=1)$ & 3 & $0(0)$ & $0(0)$ \\
\hline & Shower swab $(n=1)$ & & $0(0)$ & $0(0)$ \\
\hline \multirow{2}{*}{ Biosafety lab } & Supply water $(n=1)$ & 2 & $0(0)$ & $0(0)$ \\
\hline & Air condition $(n=1)$ & & $0(0)$ & $0(0)$ \\
\hline Total & & 12 & $0(0)$ & $4(33.33)$ \\
\hline
\end{tabular}

\section{Discussion}

The mortality associated with pneumonia due to Legionella makes it the "atypical" pathogen. ${ }^{8}$ Many first-line antibiotics commonly used to treat typical bacterial pneumonias (i.e., beta-lactams) are ineffective against Legionella species. ${ }^{18}$ This is at least partially due to the fact that Legionella are intracellular pathogens. So, there is a need for a more rapid and specific methods for timely intervention and the correct choice of antimicrobial therapy to reduce the mortality.

In this study Legionella were identified in $4.65 \%$ pneumonia patients which is a close finding of a large study in Germany among 2503 pneumonia patients showing $3.8 \%$ Legionella infection by culture, urine Ag detection and PCR. ${ }^{19}$ In the present study isolation of Legionella was 1(1.16\%) in 86 pneumonia patients. This finding is consistent to a large study conducted in Germany that reported 0.6\% Legionella isolated from 479 respiratory materials of pneumonia patients. ${ }^{19}$ Another study in Iraq also found $0.6 \%$ Legionella positive by sputum culture in 295 lower respiratory tract infection patients. ${ }^{15}$ Though a study in India in 1991 reported a higher rate $(9 \%)$ of Legionella in respiratory specimen of pneumonia patients by culture ${ }^{20}$ but recent study in South India isolated $2.55 \%$ Legionella in 470 respiratory samples by culture and biochemical analysis. ${ }^{16}$ Another study at New Delhi reported all 51 respiratory tract samples of pneumonia patients to be negative by Legionella culture. $^{21}$

Low yield of Legionella was mentioned in various studies attributed to some reasons. Legionella pneumonia is often accompanied by little sputum or other respiratory secretions. ${ }^{1}$ As a result, low number of organisms present outside of lung tissue and inhibitory effect of other bacteria of the lower respiratory tract present in the sample may reduce the sensitivity of culture. ${ }^{22}$ Moreover, other reasons for poor sensitivity of culture may be that some 
Legionella become viable but cannot be grown on routine Legionella culture media. ${ }^{1}$

In this study, out of 86 pneumonia cases, Legionella urine ICT was positive in $1(1.16 \%)$ case. This result is consistent with the study by Song et al. that reported $1.1 \%$ positive Legionella urine ICT among 648 hospitalized adult pneumonia cases in eight Asian countries. ${ }^{9}$ Miyashita et al. in Japan also reported $1.5 \%$ positive urine ICT in 400 hospitalized pneumonia patients. ${ }^{23}$ Though higher rate of infection by Legionella pneumophila $\mathrm{sg} 1$ was reported in some studies ${ }^{21}$, sensitivity of the urinary antigen detection depends on several circumstances. If the proportion of pneumonia cases included in the respective studies is not definitively caused by L.pneumophila $\mathrm{sg} 1$, the urine $\mathrm{Ag}$ test will be negative ${ }^{24}$ as urine ICT detects only $L$. pneumophila sg 1 infections. Moreover, it has been reported that $60 \%$ of Legionella pneumonia patients excrete the antigen intermittently. ${ }^{24}$ So, a negative urinary antigen result does not exclude Legionella infection.

In the present study, Legionella was detected in $4(4.65 \%)$ pneumonia patients by PCR which was almost similar to the results reported by Jonas et al. and Weir et al. ${ }^{17,25}$ The Legionella specific PCR assay described in this study targets the 16S rRNA gene which is very sensitive. ${ }^{13}$ In the present study among the four PCR positive cases, culture was positive in one case. PCR finding of this study is corroborated by other studies using conventional PCR methods and many of these authors showed PCR to have a higher rate of detection than culturebased methods. ${ }^{13,17,26-28}$

Respiratory samples may be contaminated with oropharyngeal organisms that overgrow and mask Legionella to grow in culture. $^{24}$ Another contribution to a lowered sensitivity of culture is the use of samples collected from patients currently being treated with antibiotics. A PCR test is likely to overcome these issues and indeed, PCR is considered the test of choice for patients who produce sputum by some authors. ${ }^{26}$ Though culture of respiratory samples can detect multiple species, but it may take up to five days for results. Legionella specific PCR of respiratory samples that targets a 386-bp portion of the 16S rRNA gene can be performed rapidly in 6-8 hours.

In the present study, out of 12 environmental samples, 4(33.33\%) were positive by PCR but not in culture. This finding is similar to the study by Pasculle et al., Anbumani et al., and Al-Matawah et al. ${ }^{16,29,30}$ Discrepancies between PCR and culture results in this study can be explained by several factors. Legionella growth can be inhibited or masked by overgrowth of contaminating microorganisms that leads to the poor sensitivity of water culture (10 to $30 \%) .{ }^{30}$ Furthermore, Legionella can enter a viable but noncultivable (VBNC) state, from which it can recover after passage in amoebae. ${ }^{31}$ These VBNC Legionella may be detected by PCR, along with dead bacteria, possibly explaining, why PCR values are usually higher than those obtained by culture.

This study identified high rate of Legionella (33.33\%) in environmental samples but the rate was $4.65 \%$ in pneumonia patients. A possible explanation for the relatively decreasing rate of Legionella in pneumonia patients may be a more widespread indiscriminate use of fluoroquinolones and macrolides as they are available over the counter in our country ${ }^{32}$ and Legionella is susceptible to these drugs. Prospective studies on larger number of patients are required to substantiate these findings.

This study was not designed specifically to address the epidemiologic link between presence of Legionella in environmental and public water sources and acquisition of Legionella pneumonia. This study was conducted to determine if the natural and man made water sources are contaminated with Legionella and to give the decision maker a view about the situation. In this study, Legionella has been identified from tracheal aspirates and sputum of patients admitted in the hospital with pneumonia acquired in the community. So, different water samples from ICU and medicine ward were studied so as to alert hospital infection control committee about its consequences. In Bangladesh, this study is first time performed to detect Legionella in environmental, public and hospital water samples as well as in clinical samples of pneumonia patients to identify the bacteria in these sources. A possible link between the water sources and disease transmission in population may need to be explored as there is no human to human transmission and the disease is acquired by inhalation or microaspiration of water droplets contaminated by Legionella from environmental sources.

\section{Acknowledgement}

The researcher acknowledge the support of Deparment of Microbiology and Immunology, Bangabandhu Sheikh Mujib Medical University (BSMMU), Shahbagh, Dhaka.

\section{References}

1. Bartram J, Chartier Y, Lee JV, Pond K, Surman-Lee S. World Health Organization. Legionella and the prevention of legionellosis. Geneva, Switzerland: World Health Organization; 2007.

2. Breiman RF, Butler JC. Legionnaires' disease: clinical, epidemiological, and public health perspectives. Semin Respir Infect 1998; 13: 84-89. 
3. Karagiannis I, Brandsema P, Van-der SM. Warm, wet weather associated with increased Legionnaires' disease incidence in The Netherlands. Epidemiol Infect 2009; 137: 181-87.

4. Ricketts KD, Charlett A, Gelb D, Lane C, Lee JV, Joseph CA. Weather patterns and Legionnaires' disease: a meteorological study. Epidemiol Infect 2009; 137: 1003-12.

5. Rudan I, Boschi-Pinto C, Biloglav Z, Mulholland K, Campbell H. Epidemiology and etiology of childhood pneumonia. Bulletin of the World Health Organization 2008; 86: 321-416.

6. Matsumoto T, Matsumura K, Anwar KS, Mollah AH, Murakami H, Kobayashi I, et al. Prevalence of Chlamydophila pneumoniae among Bangladeshi children under age 5 years with acute respiratory infections. J Infect Chemother 2006; 12: 139-44.

7. Vergis E, Abkas E, Yu VL. Legionella as a cause of severe pneumonia. Semin Respir Crit Care Med 2000; 21: $295-304$

8. Waterer GW, Baselski VS, Wunderink RG. Legionella and Community-Acquired Pneumonia: A Review of Current Diagnostic Tests from a Clinician's Viewpoint. The American Journal of Medicine 2001; 110: 41-48.

9. Song JH, Thamlikitkul V, Hsueh PR. Clinical and economic burden of community-acquired pneumonia amongst adults in the Asia-Pacific region. International Journal of Antimicrobial Agents 2011; 38: 108- 17.

10. Venkatesan P, Gladman J, Macfarlane JT, Barer D, Berman P, Kinnear W, et al. A hospital study of community acquired pneumonia in the elderly. Thorax 1990; 45: 254-58.

11. Morey PR. LEGIONELLA. Climate Change and Potential Effects on Microbial Air Quality in the Built Environment. Agency USEP, Translator: The Indoor Environments Division Office of Radiation and Indoor Air, 2010.

12. Diederen BM. Legionella spp. and Legionnaires' disease. J Infect 2008; 56: 1-12.

13. Cloud JL, Carroll KC, Pixton P, Erali M, Hillyard DR. Detection of Legionella species in respiratory specimens using PCR with sequencing confirmation. J. Clin. Microbiol 2000; 38: 1709-12.

14. CDC. Procedures for the Recovery of Legionella from the Environment. In: U.S. Department of Health and Human Services, ed: Centers for Disease Control and Prevention, Atlanta, GA 2005.

15. Al-Habib HM, Abdulla ZA. A Microbiological Study of Nocardia, Legionella, and Mycoplasma isolated from Lower Respiratory Tract Infections in Iraqi Patients. JIMA 2008; 40: 104.

16. Anbumani S, Gururajkumar A, Chaudhury A. Isolation of Legionella pneumophila from clinical \& environmental sources in a tertiary care hospital. Indian J Med Res 2010; 131: 761-64.

17. Jonas D, Rosenbaum A, Weyrich S, Sucharit B. Enzyme-linked immunoassay for detection of PCR- amplified DNA of Legionella in bronchoalveolar fluid. J. Clin. Microbiol 1995; 33: 1247-52.

18. Cunha BA. Severe Legionella pneumonia: Rapid presumptive clinical diagnosis with Winthrop-University Hospital's weighted point score system (modified). Heart \& Lung 2008; 37: 312-21.

19. Von-Baum H, Ewig S, Marre R, Suttorp N, Gonschior S, Welte T, et al. Competence Network for Community Acquired Pneumonia Study Group. Communityacquired Legionella pneumonia: new insights from the German competence network for community acquired pneumonia. Clin Infect Dis 2008; 46: 1356-64.

20. Agrawal L, Dhunjibhoy KR, Nair KG. Isolation of Legionella pneumophila from patients of respiratory tract disease \& environmental samples. Indian J Med Res 1991; 93: 364-65.

21. Javed S, Chaudhry R, Passi K, Sharma S, Padmaja K, Dhawan B, et al. Sero diagnosis of Legionella infection in community acquired pneumonia. Indian $\mathbf{J}$ Med Res 2010; 131:92-96.

22. Flesher AR, Kasper DL, Modern PA, Mason EO. Legionella pneumophila: growth inhibition by human pharyngeal flora. J Infect Dis 1980;142: 313-17.

23. Miyashita N, Fukano H, Mouri K, Fukuda M, Yoshida $\mathrm{K}$, Kobashi Y, et al. Community-acquired pneumonia in Japan: a prospective ambulatory and hospitalized patient study. Journal of Medical Microbiology 2005; 54: 395 400.

24. Maiwald M, Helbig JH, Luck PC. Laboratory methods for the diagnosis of Legionella infections. J Microbiol Methods 1998; 33: 59-79.

25. Weir SC, Fischer SH, Stock F, Gill VJ. Detection of Legionella by PCR in respiratory specimens using a commercially available kit. Am J Clin Pathol 1998; 110 : 295-300

26. Murdoch DR. Diagnosis of Legionella infection. Clin Infect Dis 2003; 36:64-69.

27. Lisby G, Dessau R. Construction of a DNA amplification assay for detection of Legionella species in clinical samples. Eur. J. Clin. Microbiol. Infect. Dis 1994; 13: 225-31.

28. Koide M, Saito A. Diagnosis of Legionella pneumophila infection by polymerase chain reaction. Clin. Infect. Dis 1995; 21: 199-201.

29. Al-Matawah QA, Al-Zenki SF, Qasem JA. Detection and Quantification of Legionella pneumophila from Water Systems in Kuwait Residential Facilities. Journal of pathogen 2012; 1-5.

30. Pasculle AW, Veto GE, Krystofiak S, McKelvey K, Vrsalovic K. Laboratory and clinical evaluation of a commercial DNA probe for the detection of Legionella spp. J. Clin. Microbiol 1989; 27: 2350-58.

31. Garcia MT, Jones S, Pelaz C, Millar RD, Abu Kwaik Y. Acanthamoeba polyphaga resuscitates viable nonculturable Legionella pneumophila after disinfection. Environ. Microbiol 2007; 9: 1267-77.

32. Maxmen A. On the trail of disease in Southeast Asia. J Exp Med 2009; 206: 7-10. 